\title{
Holocene tsunamigenic sediments and tsunami modelling in the Thermaikos Gulf area (northern Greece)
}

Klaus Reicherter (1), Ioannis D. Papanikolaou (2), Jean Roger (3), Christoph Grützner (1), Georgios Stamatis (2), and Dimitrios Papanikolaou (4)

(1) RWTH Aachen University, Neotectonics and Natural hazards, Geosciences, Aachen, Germany

(k.reicherter@ nug.rwth-aachen.de), (2) Laboratory of Mineralogy \& Geology, Department of Geological Sciences and Atmospheric Environment, Agricultural University of Athens, 75 Iera Odos Str., 11855 Athens, Greece, (3) Laboratoire de Géologie, Ecole Normale Supérieure, 4, rue Lhomond, 75231 Paris CEDEX 5, France, (4) Laboratory of Natural Hazards, National and Kapodistrian University of Athens, Greece

Shallow drill cores in flat and southerly exposed coastal areas around the Thermaikos Gulf (Thessalonica, northern Greece) provided evidence for past high energy sedimentary events, which are interpreted as tsunamites. A tsunamigenic source is located along the western tip of the North Anatolian Fault Zone (NAFZ) in the North Aegean Basin, where water depths ranging between 1.200 and $1.650 \mathrm{~m}$ are sufficiently deep to generate tsunamis. However, the event layers up to now cannot be assigned to individual seismic or landslide sources, but the potential of a tsunami threat in the Thermaikos Gulf area can now be tested, following both sedimentological and modelling processes. Such potential threat regarding the Thermaikos Gulf has only recently been notified but never tested and studied in depth.

As a result, several Holocene coarse clastic layers have been found intercalated in clayey or gypsiferous lagoonal deposits. These layers have erosive bases, show fining-up and thinning-up sequences, and include shell debris, foraminifera and rip-up clasts of lagoonal sediments. A widely observed significant feature of these layers involves mud-coated beach clasts, clasts that rework the high-plasticity clays of lagoons. Such features that indicate highly disturbed sedimentological condition (hyperpyncal flows) are rarely described elsewhere. Multiple intercalations of these layers with all the mentioned indicative features downhole are interpreted paleotsunami deposits from tsunamis generated by earthquakes or earthquake-triggered submarine landslides triggered by seismic shaking in the Thermaikos Gulf.

Modelling of the tsunami potential of the basin-bounding fault southwards of the Thermaikos Gulf provides an example for possible tsunami generation at only one segment of NAFZ along an approx. $55 \mathrm{~km}$ normal fault at the southern fault-bound margin of the North Aegean Basin.

The Herodotus Histories report on inundations and sea withdrawals occurring during the Greek-Persian war, which occurred near Potidea. In the ancient Greek village Mende we found evidence for a tsunamigenic layer, dated with shells to $2500 \mathrm{BP}$, which may tentatively be interpreted as the sedimentary remains of the "Herodotus tsunami" in $479 \mathrm{BC}$.

Acknowledgements: This work has been supported financially by the DAAD-IKYDA Project (Tracing tsunami deposits in the Thermaikos Gulf, Northern Greece. Implications for seismic and tsunami hazard and archaeology) and the RWTH Aachen University. 